\title{
Telangiectatic Osteosarcoma
}

National Cancer Institute

\section{Source}

National Cancer Institute. Telangiectatic Osteosarcoma. NCI Thesaurus. Code C3902.

An osteosarcoma usually arising from the metaphysis of long bones. It is characterized by the presence of a cystic architecture with blood-filled spaces. The prognosis is similar to that of conventional osteosarcoma. 